Boston University School of Law Scholarly Commons at Boston University School of Law

Faculty Scholarship

2007

\title{
Will Longer Antimicrobial Patents Improve Global Public Health?
}

Kevin Outterson

Boston Univeristy School of Law

Follow this and additional works at: https://scholarship.law.bu.edu/faculty_scholarship

Part of the Intellectual Property Law Commons

\section{Recommended Citation}

Kevin Outterson, Will Longer Antimicrobial Patents Improve Global Public Health?, 7 Lancet Infectious Diseases 559 (2007).

Available at: https://scholarship.law.bu.edu/faculty_scholarship/566

This Article is brought to you for free and open access by Scholarly Commons at Boston University School of Law. It has been accepted for inclusion in Faculty Scholarship by an authorized administrator of Scholarly Commons at Boston University School of Law. For more information, please contact lawlessa@bu.edu. 


\title{
BOSTON UNIVERSITY SCHOOL OF LAW
}

Working Paper Series, Public LaW \& Legal Theory

Working PAPER No. 07-22

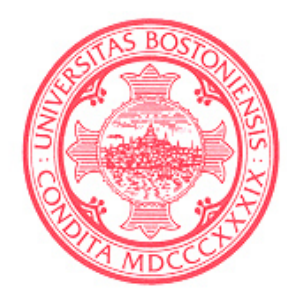

\section{Will Longer Antimicrobial Patents improve Global Public HEALTH?}

\author{
KEVIN OUTTERSON \\ JULIE BALACH SAMORA \\ KAREN KELLER-CUDA
}

This paper can be downloaded without charge at:

The Boston University School of Law Working Paper Series Index: http://www.bu.edu/law/faculty/scholarship/workingpapers/2007.html

The Social Science Research Network Electronic Paper Collection: http://ssrn.com/abstract $=1009296$ 


\section{Will longer antimicrobial patents improve global public health?}

Kevin Outterson, Julie Balch Samora, Karen Keller-Cuda

\begin{abstract}
The problem of antimicrobial resistance has led some infectious disease experts and their professional societies to propose the use of transferable intellectual property rights (wildcard patents) and patent term extensions as methods to encourage antimicrobial research and development. We evaluate recent approvals of new antimicrobial classes and find that the number of new introductions is higher than previously suggested. More importantly, creating new patent rights is shown to be an inefficient and possibly counterproductive response to antimicrobial resistance. Wildcard patents would operate as a more than US\$40 billion annual tax on heart disease, hypertension, chronic obstructive pulmonary disease, asthma, and depression to inefficiently cross-subsidise antimicrobial research and development. Patent term extensions would likewise cost more than \$5 billion per year, hinder access, and allocate resources inefficiently. Alternative uses for these funds are proposed, with greater potential positive effects on global public health. Additional public funding of antimicrobial research could be a more effective use of these funds. Conservation efforts to encourage the prudent use of antimicrobial drugs should be directly reimbursed. Patent owners should be compensated for both conservation efforts and valuable innovation.
\end{abstract}

\section{Introduction}

Antimicrobial agents are valuable resources for global public health. As microbial resistance progresses, each new pharmaceutical molecule represents a potentially exhaustible innovation, similar in some ways to natural resources such as fossil fuels. ${ }^{1}$ Society could respond to antimicrobial exhaustion in two ways: (1) production of novel antimicrobial drugs through research and development (the supply-side production response), and (2) conservation of existing antimicrobial drugs through research, development, and implementation of prudent techniques of antimicrobial therapy to maximise effectiveness, delay resistance, and conserve resources (the demand-side conservation response). In recent publications, leading academic groups have evaluated the medical need for additional antimicrobial drugs. These groups include the Infectious Diseases Society of America (IDSA), ${ }^{2,3}$ the European Society of Clinical Microbiology and Infectious Diseases (ESCMID), ${ }^{4}$ a European Union (EU) Intergovernmental Conference, ${ }^{5}$ the US Institute of Medicine, ${ }^{6}$ the UK Commission on Macroeconomics and Health, ${ }^{7}$ and others. ${ }^{8,9}$ The groups find the research and development pipeline to be insufficient. Among a host of recommendations, several of these reports propose supply-side strategies such as extending patent terms for antimicrobial drugs and creating patent rights that can be transferred to other drugs, a "transferable intellectual property right" (TIPR) or "wildcard" patent. ${ }^{2-5,8}$ Wildcard patents have been proposed in two prominent bills in the US Congress, supported in part by such reports..$^{10,11}$

The case for wildcards and patent extensions is founded upon two claims. First, that we face an unprecedented drought in the discovery of novel antimicrobial classes, and second, that changes to the patent system are therefore indicated. In this Personal View, we examine both propositions. We review the claim that drug companies are failing to deliver new antimicrobial classes, but most importantly we highlight how patent extension will operate as a global tax on treatments for common diseases while inefficiently cross-subsidising antimicrobial research.

\section{Is the antimicrobial research and development} pipeline empty?

The following discussion is a Sisyphean task, an attempt to characterise the glass as half full rather than half empty. We recognise that resistance drives the clinical need for additional antimicrobial drugs, the importance of prudent use of antimicrobial drugs, ${ }^{12,13}$ and that every physician would prefer to have better weapons against infectious disease. Our purpose in this section is quite limited; we seek only to question certain elements of the claims by IDSA, ${ }^{2,3}$ ESCMID ${ }^{4}$ and others, ${ }^{5,6,8}$ concerning the alleged dearth of new antimicrobial class introductions. We are particularly interested when these statistics are used as a warrant to legislate for patent extensions and wildcard patents in Europe and the USA. The patent extension agenda seems to include only partly examined risks for the treatment of infectious diseases.

At least five major reports since 2003 have discussed the small number of new antimicrobial class introductions. ${ }^{2,46,8}$ The updated IDSA report in March, 2006, followed a different methodology, listing specific high-priority pathogens for which few drugs were in development. ${ }^{3}$ In the present article, we address only the class-based claims.

Recent regulatory approval of at least three-and arguably five-new classes discounts the claim that new antimicrobial classes are not being introduced. Of the 15 (or 17) antimicrobial classes introduced into clinical practice since the $1930 \mathrm{~s}$, three (or five) have been introduced to the market since September, 1999 (panel). Three of these approvals occurred before the publication of the 2004 IDSA monograph Bad Bugs, No Drugs. ${ }^{2}$ Although several of these new drugs have substantial
Lancet Infect Dis 2007; 7: 559-66

Boston University School of Law, Boston, MA, USA (K Outterson LLM); and West Virginia University School of Medicine, Department of Physiology and Pharmacology (J B Samora MPH), West Virginia University, Morgantown, WV, USA (K Keller-Cuda JD)

Correspondence to: Kevin Outterson, Boston University School of Law, 765 Commonwealth Ave, Boston, MA 02215, USA. Tel +1 6173533103 ; $\mathrm{fax}+16173533077$ mko@bu.edu 
Panel: Novel antimicrobial classes, by decade of market introduction

1930s

Sulfonamides

1940s

Penicillins

Cephalosporins

Aminoglycosides

Chloramphenicol

1950s

Tetracyclines

Macrolides

Glycopeptides

Rifamycins

1960s

Quinolones

Lincosamides

Trimethoprim

2000 s

Streptogramins*

Oxazolidinones

Lipopeptides

Ketolides $†$

Glycylcyclines $\dagger$

*The first injectable streptogramin for human use was approved in September, 1999, in the USA and December, 1999, in the EU, but significant sales did not occur in 1999, particularly in Europe. Accordingly, streptogramins are placed in the 2000 decade of market introduction. TKetolides and

glycylcyclines are arguably categorised as new classes, although they are related

to existing classes. This issue is discussed more fully in the text.

limitations, since they are first-in-class compounds we can expect follow-on innovation attempting to extend the effectiveness and safety of the classes.

Quinupristin/dalfopristin was the first injectable streptogramin approved for human use, approved by the US Food and Drug Administration (FDA) in September, 1999, and the EU in December, 1999. Although streptogramins are related to macrolides and lincosamides, ${ }^{9,14}$ much of the published work characterises streptogramins as a separate class with an innovative mechanism of action and effective resistance profiles, particularly streptogramin A (dalfopristin)..$^{15-23}$ The current US licensee, Monarch Pharmaceuticals Inc, describes quinupristin/dalfopristin as "the first streptogramin - the first new antibiotic class available to the United States medical community in over a decade." ${ }^{24}$ Several reports list streptogramins as "developed" or "introduced" in the 1960s, ${ }^{4,5}$ although the product remained on the shelf for decades before regulatory approvals in the USA and the EU in 1999. US sales have been modest. ${ }^{25}$

Linezolid, the first oxazolidinone, was introduced to the USA in 2000. Sales in the EU followed in 2001.
Linezolid won approval for a label extension for paediatric patients with Gram-positive infections in 2002 and for bacterial infections in paediatric patients in May, 2005. ${ }^{26}$ Linezolid is now marketed by Pfizer, with global sales of \$618 million in 2005. ${ }^{27}$

Daptomycin, the first lipopeptide, became available in the USA in September, 2003. ${ }^{28-30}$ Marketing approval in the EU came in January, 2006. Cubist Pharmaceuticals reports that daptomycin has had the fastest and most impressive sales growth of any intravenous antibiotic launched in recent history. Cubist is developing followon lipopeptides. ${ }^{31}$ The indications for daptomycin use might also be extended. On March 6, 2006, the FDA AntiInfective Drug Advisory Committee considered Cubist Pharmaceutical's request for an expansion for daptomycin to treat patients with Staphylococcus aureus bacteraemia, including patients with suspected endocarditis caused by meticillin-susceptible and meticillin-resistant strains. ${ }^{32}$ The FDA approved the label extension on May 25, 2006.

In April, 2004, the FDA approved telithromycin, a ketolide. Approval in the EU came several years earlier, in October, 2001, before the publication of Bad Bugs, No Drugs. Ketolides are structurally related to macrolides; however, they are frequently described as a new class with unique resistance profiles. ${ }^{9,33-36}$ Telithromycin is marketed by Sanofi-Aventis, and is indicated for the treatment of serious bacterial infections, such as community-acquired pneumonia (including multidrugresistant Streptococcus pneumoniae), acute bacterial sinusitis, and acute exacerbation of chronic bronchitis. ${ }^{37}$ Even though reports suggest serious hepatotoxicity issues, ${ }^{38,39}$ research teams at Chiron and Abbott Laboratories are working on follow-on ketolides with antibacterial activity. ${ }^{40,41}$

In June, 2005, the most recent antimicrobial class was approved by the FDA. EU approval followed in May, 2006. Wyeth's tigecycline is the first drug in the glycylcycline class. ${ }^{42-46}$ Analysts expect tigecycline to be a successful and bestselling drug. ${ }^{47}$ Tigecycline is active against both Grampositive and Gram-negative bacteria, including antimicrobial-resistant bacteria such as meticillin-resistant $S$ aureus (MRSA), vancomycin-resistant Enterococcus faecalis and Enterococcus faecium, and extended-spectrum beta-lactamase-producing Enterobacteriaceae. ${ }^{42,43}$

Spellberg and colleagues question whether ketolides and glycylcyclines are properly characterised as a novel mechanism. ${ }^{9}$ Some of the published work describes streptogramins ${ }^{14}$ and ketolides ${ }^{9,33-36}$ as structurally related to macrolides. We have followed the terminology used by much of the literature, ${ }^{15-23,33-36,42-46}$ but concede that it is not entirely clear what differentiates a new antimicrobial class from its structurally related or derivative kin. When the topic is antimicrobial resistance and related potential legislative responses, we suggest that distinct molecules that present unique modes of action or resistance profiles could be deemed as new classes. Streptogramins possess a novel mechanism of action and resistance profile. ${ }^{15-23}$ 
Tigecycline, although related to tetracyclines, presents unique barriers to tetracycline resistance (both efflux pumps and ribosomal protection). ${ }^{44,48,49}$ Ketolides also offer improved antimicrobial activity and resistance profiles. ${ }^{33-36,48}$

Rather than engage in taxonomical reductionism, we should consider the purpose for this analysis, which is to study the record of recent innovation. At a minimum, the definition of class should be temporally consistent. If structurally related groups are to be combined in a single class, then perhaps tetracyclines, macrolides, glycopeptides, and quinolones are a single class. If so, the record of class introductions since 2000 is even more impressive.

The pharmaceutical industry has introduced three (or five) new antimicrobial classes for human use since 1999, compared with none between 1968 and 1999 (panel). Although discovery of additional antimicrobial drugs is always welcome and likely to be needed, the current research and development environment is not entirely bleak. In any case, no one should assume that wildcard patents and patent extensions are the correct response to the current situation.

\section{Will longer patents improve global public health?}

We will now evaluate the claim that wildcards and patent extensions are the correct mechanisms to stimulate antimicrobial innovation and therefore improve global public health. The existing published work emphasises that the patent system entails both costs and benefits to patients and society. ${ }^{50-53} \mathrm{Bad}$ Bugs, No Drugs, ${ }^{2}$ and similar reports ${ }^{3-5,8}$ did not adequately examine the potential costs of wildcards and patent extensions.

\section{Wildcard patents}

Wildcard patents sever the historic connection between innovation and reward. The proposal is a pronounced departure from global patent law. It disengages the market from patents, substituting a government-driven bureaucratic process. Wildcards of up to 2 years have been proposed in the US Congress. ${ }^{10,11}$ In Europe, researchers have modelled wildcard patents of 5 years or longer. . $^{54,55}$

The wildcard proposal grants longer patent life to a bestselling drug if a company delivers a different antimicrobial drug to the market. ${ }^{54-58}$ In short, market a new antimicrobial and obtain a 2-year patent extension on a blockbuster drug such as atorvastatin (Lipitor). Wildcard patents provide an incentive for companies to deliver more antimicrobial drugs, but the costs may be staggering. A 2-year wildcard patent extension on the top ten selling drugs would protect more than $\$ 125 \cdot 3$ billion in global annual sales from generic competition. The global cost of granting just ten wildcard patent extensions will likely exceed $\$ 40$ billion, more than $\$ 4$ billion per new drug (table). If the wildcard proposal allows stacking of multiple extensions on a single blockbuster drug, then the cost might double.

These figures do not include the actual cost of purchasing the new drugs, associated tax credits for research and development and orphan drug status (more than half of research and development expenditures may qualify), or government grants supporting the research (approximately half of biomedical research and development is funded by governments). If the new antimicrobial is well-received by the market, these additional acquisition costs can be substantial. Linezolid's 2005 sales have a net present value of $\$ 6.9$ billion over 10 years (assuming a $10 \%$ annual sales growth and a $6 \%$ discount rate; without price increases the net present value still exceeds $\$ 4.5$ billion). Tax credits for research and development will also add to the cost substantially. The industry estimates their research and development costs at a similar amount per new drug. If so, tax credits and government grants may well increase the cost by $\$ 800$ million more. Wildcard patents will therefore require spending in the range of $\$ 8.7$ billion to $\$ 11.9$ billion per delivered antimicrobial drug, greatly exceeding the industry's estimates of $\$ 800$ million per new molecule by an order of magnitude.

The quality of the delivered antimicrobial drug is also at issue. Under the recently proposed US BioShield II legislation, drug companies would qualify for a wildcard if a patented antimicrobial drug was contracted to the US government for military or antiterrorism use. Existing drugs could qualify, and drugs could earn this designation for a very narrow indication or with modest effectiveness. ${ }^{10,57,60,61}$ The US experience with exclusive marketing extensions for orphan drugs and paediatric testing is illustrative. Rofecoxib was approved by the FDA as an orphan drug for juvenile rheumatoid arthritis on March 16, 2004, ${ }^{62}$ a few months before Merck withdrew it from the worldwide market.

\begin{tabular}{|c|c|c|c|}
\hline & $\begin{array}{l}2005 \text { sales } \\
\text { ( } \$ \text { billion) }\end{array}$ & $\begin{array}{l}\text { Protected } \\
\text { sales ( } \$ \text { billion) }\end{array}$ & $\begin{array}{l}\text { Cost } \\
\text { (\$ billion) }\end{array}$ \\
\hline Lipitor (atorvastatin) & $12 \cdot 9$ & $28 \cdot 3$ & $9 \cdot 4$ \\
\hline Plavix (clopidogrel bisulfate) & $5 \cdot 9$ & $14 \cdot 8$ & 4.9 \\
\hline Nexium (esomeprazole) & $5 \cdot 7$ & $14 \cdot 4$ & $4 \cdot 8$ \\
\hline $\begin{array}{l}\text { Seretide/Advair (fluticasone } \\
\text { propionate-salmeterol xinafoate) }\end{array}$ & $5 \cdot 6$ & $14 \cdot 6$ & $4 \cdot 9$ \\
\hline Zocor (simvastatin) & $5 \cdot 3$ & 8.9 & $3 \cdot 0$ \\
\hline Norvasc (amlodipine besilate) & $5 \cdot 0$ & $10 \cdot 4$ & $3 \cdot 5$ \\
\hline Zyprexa (olanzapine) & $4 \cdot 7$ & $8 \cdot 5$ & $2 \cdot 8$ \\
\hline Risperdal (risperidone) & $4 \cdot 0$ & $9 \cdot 6$ & $3 \cdot 2$ \\
\hline Ogastro/Prevacid (lansoprazole) & $4 \cdot 0$ & $8 \cdot 1$ & $2 \cdot 7$ \\
\hline Effexor (venlafaxine) & $3 \cdot 8$ & $7 \cdot 7$ & $2 \cdot 6$ \\
\hline Total & $56 \cdot 9$ & $125 \cdot 3$ & $41 \cdot 8$ \\
\hline \multicolumn{4}{|c|}{$\begin{array}{l}2005 \text { sales data from IMS MIDAS, MAT Dec } 2005 \text { (IMS Health). }{ }^{59} \text { Protected sales are authors' extrapolations from } \\
\text { IMS } 2005 \text { sales growth (or loss) for each drug in constant US\$. Cost is estimated at one-third of wholesale prices, } \\
\text { reflecting estimated averted generic competition. In the USA, multiple generic entry frequently drives branded prices } \\
\text { down by more than a third. }\end{array}$} \\
\hline
\end{tabular}


The qualification criteria for wildcard patents will be a government-driven bureaucratic process, rewarding pharmaceutical companies with billions of dollars in protected markets. The potential for mistake and rentseeking is strong, particularly if the criteria and processes are not fully transparent. For example, the value of wildcard patents will decline as more are issued. A modest follow-on drug, if certified first, could be worth more than $\$ 9$ billion if it extends atorvastatin by 2 years. A truly innovative first-in-class drug, approved a few years later, would generate much smaller wildcard rewards. This will create pressure for a prioritisation system or additional costly incentives. ${ }^{54,5,57,60,61}$ A prioritisation system should evaluate antimicrobial innovations based upon expected clinical effectiveness, not unlike the cost-effectiveness systems used in Australia's Pharmaceuticals Benefit Scheme (PBS), the UK's National Institute for Health and Clinical Excellence (NICE), and the Institute for Quality and Economic Efficiency in Health Care in Cologne, Germany. These programmes are frequently criticised by the patent-based drug companies.

Wildcard proposals also raise serious questions about equity and transparency. Companies are likely to transfer the wildcard from the qualifying drug (an antimicrobial) to their bestselling patented drug. The bestselling drugs in the world treat conditions such as heart disease, high blood pressure, asthma, chronic obstructive pulmonary disease, gastroesophageal reflux disease, and depression. A 2-year patent extension on atorvastatin protects $\$ 28.3$ billion in sales from generic competition (table). Wildcard patents are essentially a hidden tax on heart disease, depression, and other common ailments to fund antimicrobial research and development. ${ }^{55,57,60,61}$ Direct financing would be more transparent and efficient, especially since the projected cost per drug exceeds the industry's average research and development costs by a factor of ten or more.

\section{Patent extensions}

The second patent-related proposal is to extend the patents for antimicrobial drugs, giving the companies a longer effective patent life. ${ }^{3,54}$ Patented drugs in the USA are eligible for patent extensions under the HatchWaxman Act, to compensate for a portion of the time lost in regulatory approval. In the EU, Supplementary Protection Certificates serve the same function. Similar extensions are granted in other countries, as well as for orphan drugs and drugs tested for paediatric indications. A new proposal is to grant additional patent extensions for antimicrobial drugs. ${ }^{3,54}$ We regard longer antimicrobial patents to be financially inefficient as an innovation mechanism, clinically detrimental when patients are denied financial access to needed therapy, and counterproductive to important conservation strategies that encourage the appropriate use of antibiotics. Longer patents are unlikely to improve health; at the very least, the hypothesis should not be assumed to be true.

\section{Patent taxes and innovation}

Patents and similar laws allow companies to impose a "patent tax" (technically, pharmaceutical patent rent appropriation) upon consumers and insurers through higher prices during the period of marketing exclusivity. Additional patent taxes are an inefficient method for funding additional antimicrobial research and development.

For antimicrobial drugs that decrease in clinical effectiveness over time, the prospective financial effect of an additional year of patent protection is small, since sales in the additional year will tend to be depressed by resistance and competition from follow-on drugs. Longer patent periods for antimicrobial drugs might actually encourage companies to postpone investment in novel antimicrobials. The looming threat of patent expiration is a powerful incentive to produce new blockbuster drugs; longer patents only postpone the day of reckoning. If patent periods were extended, it is quite possible that the effect on antimicrobial innovation will be modest or perhaps negative. ${ }^{63}$

Longer patent terms are not an efficient way to fill the research and development pipeline. Roughly $17 \cdot 5 \%$ of this incremental patent tax revenue would be funnelled into research and development, if one assumes as correct the data provided by PhRMA, the US trade association for patent-based drug companies. ${ }^{64}$ Global sales of antimicrobial drugs in 2005 were about $\$ 26$ billion..$^{59}$ If widespread antimicrobial patent extensions increased pharmaceutical patent rents by an additional $20 \%$, then antimicrobial patent taxes would increase by $\$ 5.2$ billion. This cash flow would yield only $\$ 910$ million in additional research and development (assuming $17.5 \%$ of cash flow is directed to research and development). The other $\$ 4.29$ billion will be spent on other corporate expenses and profits. Nor is there any binding commitment that any incremental research and development would actually focus on antimicrobial drugs, since a bureaucratically enforced mandate and audit is absent. Even if the entire sum were applied to antimicrobial research, industry estimates suggest that only one new antimicrobial drug would be developed per year, after a delay of more than a decade.

Policymakers are unable to say whether the present level of pharmaceutical patent rent appropriation is optimal, sub-optimal, or supra-optimal. The data to make this determination are not available in a transparent, trustworthy platform..$^{53}$ Before governments impose multibillion dollar patent taxes on consumers, we should have some idea of whether that money will be spent wisely, or whether other priorities would better serve public-health needs.

\section{Patent taxes and financial access}

One pronounced weakness of using the patent system to increase antimicrobial research and development is the negative effect of drug costs on patient access. Longer 
patent periods will delay generic entry. Drug prices will remain at high levels for longer periods of time. This burden falls most sharply on individuals lacking insurance for prescription drugs or individuals who are unable to afford them. Pharmaceutical patents stand between patients and the care they need by placing an artificially high price on important drugs. ${ }^{53,63}$ In countries with public financing of pharmaceutical benefits, the burden falls on the health insurance system, diverting resources away from other priorities. The money for patent taxes comes from the health system, and ultimately, the people. One study estimated substantial losses in consumer welfare (health) if an important class of antimicrobial drugs had been patented in India in recent decades. ${ }^{65}$

\section{Patent taxes and the prudent use of antimicrobial drugs}

Patent-based incentive systems are frequently at odds with the prudent use of antimicrobial drugs. The patent owner may choose to maximise current sales rather than carefully conserve the antimicrobial drug for society's long-term benefit. With only a few years remaining on the patent, the company faces financial incentives to maximise sales through marketing, even if global public health would call for much more judicious use of the drug. ${ }^{7,52,53,63,66-69}$ We call this situation "patent-holder waste". Under English common law, the owner of a timelimited property right (a tenant or holder of a life estate) could be held accountable for wasting the long-term value of the property. One example was clear cutting timber in the last year of a lease: facing the expiration of a property right, the tenant could be tempted to maximise short-term economic returns. By 1278, the Statute of Gloucester provided for treble damages for such waste.

A possible example of patent-holder waste is linezolid. Linezolid was approved for marketing in the USA in April, 2000. Sales of linezolid have escalated globally, becoming one of the leading antimicrobial drugs in the world..$^{70}$ The time-limited nature of the patent creates an incentive to promote and sell more than the socially optimum amount of antimicrobials..$^{52,63,69}$ In July, 2005, the FDA issued a warning letter to Pfizer concerning its overzealous marketing of linezolid. ${ }^{71}$

A second possible example of patent-holder waste is telithromycin. Sanofi-Aventis planned to market this new antimicrobial drug for otitis media and tonsillitis in children ${ }^{72}$ - clinical indications prone to antimicrobial misuse. ${ }^{12}$ After reports of liver damage, the FDA urged Sanofi-Aventis in May, 2006, to halt the paediatric trials and the company suspended additional enrolment in June, 2006..$^{72,73}$ Aside from the issue of potential hepatotoxicity, the more immediate question is why Sanofi-Aventis was planning to mass-market telithromycin to children for ear infections and sore throats? The patent holder's proclivity towards shortterm and company-focused thinking when facing rent truncation should be recognised as wasting a potentially exhaustible resource. Patent-based incentives are often inconsistent with antimicrobial conservation measures, which necessarily limit the demand for novel antimicrobial drugs.

A third possible example of waste is Bayer's sale of the animal antibiotic enrofloxacin (Baytril), which threatened to speed resistance to other members of the quinolone class, including Bayer's ciprofloxacin.

Horowitz and Moehring ${ }^{69}$ and Kades $^{68}$ have suggested the use of longer antimicrobial patents as demandrationing devices. This strategy is unworkable for many reasons. Consider the difficulty when patents for drugs in an antimicrobial class are held by different owners, or when one or more of the drugs in class are off-patent. Joint property owners are exposed to the tragedy of the commons, and are thereby prone to waste. ${ }^{63,69}$ If the number of patent holders within the class is quite small, then perhaps private coordination can prevent overzealous marketing and delay resistance. Competition laws might need to be modified to permit this joint coordination among rival companies. When one or more drugs in a class are off-patent, private coordination cannot work, because there are reduced barriers to entry by a nonconforming and profit-maximising generic producer. ${ }^{69} \mathrm{~A}$ patent-based solution to these issues would require a very broad patent for the entire drug class to the first applicant. ${ }^{63,67}$ The first company to patent a new target or mode of action would have to control the licensing of all downstream innovation, and thus manage the entire class. The social welfare costs of this monopoly are not clear. In any event, class-based patents would require a fundamental overhaul of global patent law and are probably inconsistent with the World Trade Organization Trade-Related Aspects of Intellectual Property Rights agreement. $^{63}$

\section{Alternatives to longer patents}

We suggest that funds earmarked by the patent-based drug industry for wildcards and patent extensions could be more thoughtfully applied to other approaches with greater positive effect on global public health.

\section{Reimburse providers for antimicrobial conservation}

Patent-based approaches entail substantial fiscal and health costs. Additional resources might be better spent on conservation efforts to stave off antimicrobial resistance. Conservation reduces demand through the familiar techniques of health promotion, infection control, sanitation, improved diagnostic testing, stewardship of available antimicrobial drugs, subsidies for preferred therapies, and otherwise prolonging the useful therapeutic lives of existing antimicrobial drugs. Researchers and professional societies have made the case for substantial conservation efforts for many years. $^{2,5-8,12,13,52,74}$

A major problem with conservation is reimbursement: virtually no one pays for antimicrobial conservation. In 
the USA the opposite occurs: hospitals are reimbursed for nosocomial infections. This is a travesty of the highest order. Many proven techniques could be encouraged through changes in reimbursement. The wildcard proposal could cost more than $\$ 40$ billion per year. Imagine the effect if even a tenth of that sum were spent on conservation. Health-care providers should receive substantial financial rewards for achieving benchmarks in infection control and the appropriate use of antimicrobial drugs.

Another area for conservation involves creating better diagnostic tests to determine the type of infection and its susceptibility status before antimicrobials are administered empirically. This suggestion was made in 1994 by the American Society for Microbiology's Task Force on Antibiotic Resistance, ${ }^{74}$ and has been repeated many times since. $^{5,12}$ In community settings, prescription of antimicrobial drugs for viral infections is unfortunately common. This practice could be curtailed with a truly effective, inexpensive, and speedy out-patient diagnostic test. In the hospital, precise, speedy, and inexpensive tests for MRSA would be useful. For example, a new molecular screening test uses quick, multiplex immunocapturecoupled PCR that could be promoted to rapidly identify previously unknown MRSA carriers and to reduce crossinfections. ${ }^{75,76}$ Additional funding and reimbursement guarantees could promote diagnostic innovation.

There are many opportunities to encourage appropriate use of antimicrobial drugs. Conserving antimicrobial drugs for human use might require restrictions on animal use, ${ }^{68,7}$ an approach the FDA has recently adopted, ${ }^{78}$ following Europe's lead..$^{79}$ In resource-poor settings, direct financial subsidies for preferred therapies might be required. A subsidy plan for artemisinin-based combination therapy for malaria in developing countries is one example. ${ }^{80}$ Otherwise, widespread use of artemisinin monotherapy will speed the development of resistance. The inadvertent conservation of chloroquine in Malawi was achieved by removing the drug from the market for 12 years. ${ }^{81}$ Conservation and restoration may be much cheaper than creating an entirely new antimalarial drug. Many other cost-effective global public-health targets could be identified if we knew that billions of dollars were available to be spent.

\section{Increase public funding of antimicrobial research and development}

A more efficient mechanism for improving global public health should consider pronounced increases in government research budgets for antimicrobial research, including new drugs, conservation, and diagnostics. ${ }^{6,7,13}$ In the discussion above, we estimated that patent term extensions would cost $\$ 5 \cdot 2$ billion per year in additional patent taxes. Patent extensions are favoured by $\mathrm{Kades}^{68}$ who suggests that private research and development is more efficient than publicly funded research and development. Assuming for the sake of argument that the private sector is twice as efficient, then spending $\$ 5.2$ billion on government grants would result in approximately 2.8 times more effective antimicrobial research. If we want more agents that are effective against pathogens, the most direct and efficient route may be to greatly increase long-term government grants from the US National Institutes of Health and their counterparts throughout the Organisation for Economic Co-operation and Development. Another attractive candidate would be a prize-based system to incentivise innovation, as recently proposed by several economists and researchers. ${ }^{82,83}$ An additional $\$ 5.2$ billion per year would represent a substantial increase in antimicrobial research and development.

\section{Compensate the patent owner for conservation}

For some antimicrobial drugs, global public health would be best served by temporarily holding the drug off the market, or by severely restricting its use for a period of time to stave off resistance. The patent owner could rightly complain that conservation efforts reduced its profits on the drug. If a drug regulatory authority holds an approved drug off-market as a conservation plan, innovation policy might call for the patent owner to be compensated. ${ }^{63,69}$ This compensation could take the form of direct payments, a full patent buyout, ${ }^{84}$ or patent extensions for the off-market period, similar to HatchWaxman. Ideally, the mechanism would be coordinated globally since resistance is a global phenomenon.

\section{Compensate the patent owner for valuable innovation}

Companies report dissatisfaction with the antimicrobial marketplace. ${ }^{2,8,85}$ For chronic conditions such as heart disease, prescriptions will be taken daily for many years. Antibiotics are typically administered episodically, requiring fewer pills to complete a course of treatment. Insurance companies and government-funded pharmaceutical purchasers have been reluctant to pay substantially higher prices for antimicrobial drugs.

The most direct approach would be to ensure that reimbursement prices for antimicrobial drugs are set high enough. Private and public insurers should not seek to minimise drug prices at all costs, but should reward outstanding innovation appropriately. Put another way, the industry needs to make a cost-effectiveness argument for higher antimicrobial reimbursement. In recent years, the industry has introduced some very expensive oncology drugs, defending the prices on cost-effectiveness grounds. Evidence abounds that dangerous infections cost insurers, hospitals, and society at large thousands of dollars per case. ${ }^{5}$ The most market-based remedy for inadequate innovation is to pay more for outstanding innovation. Governments are the largest purchasers of antimicrobial drugs; cost-effectiveness should become part of the reimbursement process. Higher prices might also discourage imprudent use of antimicrobial drugs and otherwise support conservation efforts. ${ }^{63,68}$ One 
difficulty with this approach is ensuring access for patients with limited financial means.

\section{Conclusion}

Health-care providers seek effective clinical options for patients with serious infections. Whereas the patentbased pharmaceutical industry seeks wildcard patents and patent term extensions, the public's health might be better served by increasing direct public funding for antimicrobial research, reimbursing providers for infection control, creating innovative diagnostic tests and antimicrobial drugs, and otherwise investing in conservation.

\section{Conflicts of interest}

We declare that we have no conflicts of interest.

\section{References}

1 Ramanan Laxminarayan, ed. Battling resistance to antibiotics and pesticides: an economic approach. Washington, DC: RFF Press, 2003.

2 IDSA. Bad bugs, no drugs: as antibiotic discovery stagnates... public health crisis brews. Alexandria, VA: Infectious Diseases Society of America, 2004. http://www.idsociety.org/pa/IDSA Paper4_final_web.pdf (accessed May 24, 2007).

3 Talbot GH, Bradley J, Edwards JE, Gilbert D, Scheld M, Bartlett JG. Bad bugs need drugs: an update on the development pipeline from the Antimicrobial Availability Task Force of the Infectious Diseases Society of America. Clin Infect Dis 2006; 42: 657-68.

4 Norrby SR, Nord CE, Finch R. Lack of development of new antimicrobial drugs: a potential serious threat to public health. Lancet Infect Dis 2005; 5: 115-19.

5 Finch R, Hunter RA. Antibiotic resistance-action to promote new technologies: report of an EU Intergovernmental Conference held in Birmingham, UK, 12-13 December 2005. J Antimicrob Chemother 2006; 58 (suppl 1): i3-22.

6 Smolinski MS, Hamburg MA, Lederberg J, eds. Microbial threats to health: emergence, detection, and response. Washington, DC: National Academies Press, 2003.

7 Smith RD, Coast J. Global responses to the growing threat of antimicrobial resistance. Commission on Macroeconomics and Health working paper WG2:17, 2002. http://www.cmhealth.org/ docs/wg2_paper17.pdf (accessed May 24, 2007).

8 Wenzel RP. The antibiotic pipeline-challenges, costs, and values. $N$ Engl J Med 2004; 351: 523-26.

9 Spellberg B, Powers JH, Brass EP, Miller JG, Edwards JE. Trends in antimicrobial drug development: implications for the future. Clin Infect Dis 2004; 38: 1279-86.

10 Biological, Chemical, and Radiological Weapons Countermeasures Research Act (BioShield II). S.666, 108th Congress.

11 Protecting America in the War on Terror Act of 2005. S.3, 109th Congress.

12 Levy SB. The antibiotic paradox: how the misuse of antibiotics destroys their curative powers. 2nd edn. Cambridge, MA, USA: Perseus Publishing, 2002.

13 WHO. Rational use of medicines: progress in implementing the WHO medicines strategy. Geneva: World Health Organization, May 11, 2006. EB118/6.

14 Powers JH. Antimicrobial drug development-the past, the present, and the future. Clin Microbiol Infect 2004; 10 (suppl 4): 23-31.

15 Manfredi R. A re-emerging class of antimicrobial agents: streptogramins (quinupristin/dalfopristin) in the management of multiresistant Gram-positive nosocomial cocci in hospital setting. Mini Rev Med Chem 2005; 5: 1075-81.

16 Manzella JP. Quinupristin-dalfopristin: a new antibiotic for severe Gram-positive infections. Am Fam Physician 2001; 64: 1863-66.

17 Bofiglio G, Furneri PM. Novel streptogramin antibiotics. Expert Opin Investig Drugs 2001; 10: 185-98.

18 Wood MJ. Chemotherapy for Gram-positive nosocomial sepsis. J Chemother 1999; 11: 446-52.
19 Beyer D, Pepper K. The streptogramin antibiotics: update on their mechanism of action. Expert Opin Investig Drugs 1998; 7: 591-99.

20 Barriere JC, Berthaud N, Beyer D, Dutka-Malen S, Paris JM, Desnottes JF. Recent developments in streptogramin research. Curr Pharm Des 1998; 4: 155-80.

21 Rubinstein E, Bompart F. Activity of quinupristin/dalfopristin against Gram-positive bacteria: clinical applications and therapeutic potential. J Antimicrob Chemother 1997; 39 (suppl A): 139-43.

22 Pechere JC. Streptogramins. A unique class of antibiotics. Drugs 1996; 51 (suppl 1): 13-19.

23 Low DE. Quinupristin/dalfopristin: spectrum of activity, pharmacokinetics, and initial clinical experience. Microb Drug Resist 1995; 1: 223-34.

24 King Pharmaceuticals Inc. Synercid iv, quinupristin/dalfopristin: about. http://www.kingpharm.com/synercid/html/about.htm (accessed May 24, 2007).

25 King Pharmaceuticals Inc. Annual report, form 10-K filed with the US Securities and Exchange Commission, Dec 31, 2005. Washington, DC: King Pharmaceuticals Inc, 2005.

26 Pharmacia Corporation. Annual report, form 10-K, filed with the US Securities and Exchange Commission, Dec 31, 2002. Washington, DC: Pharmacia Corporation, 2002.

27 Pfizer Inc. Annual report, form 10-K, filed with the US Securities and Exchange Commission, Dec 31, 2005. Washington, DC: Pfizer Inc, 2005.

28 Kern WV. Daptomycin: first in a new class of antibiotics for complicated skin and soft-tissue infections. Int J Clin Pract 2006; 60: $370-78$.

29 Kaufman M. FDA approves new antibiotic for resistant bacteria. Washington Post (Washington, DC), June 17, 2005: A14.

30 Eisenstein BI. Lipopeptides, focusing on daptomycin, for the treatment of Gram-positive infections. Expert Opin Investig Drugs 2004; 13: 1159-69.

31 Cubist Pharmaceuticals Inc. Serious infections. Serious business. Biotechnology Industry Organization Bio CEO \& Investor Conference; New York, NY; Feb 15, 2006. http://www.cubist.com (accessed March 1, 2006).

32 FDA Advisory Committee. Summary minutes of the Anti-Infective Drugs Advisory Committee meeting on March 6, 2006. Washington, DC: US Food and Drug Administration Center for Drug Evaluation and Research, 2006. http://www.fda.gov/ohrms/dockets/ac/06/ minutes/2006-4209M.pdf (accessed June 28, 2007).

33 Elliot VS. FDA approves first ketolide antibiotic. American Medical News (Chicago), April 26, 2004. http://www.ama-assn.org/ amednews/2004/04/26/hlsc0426.htm (accessed May 24, 2007).

34 Nord CE, Farrell DJ, Leclercq R. Impact of ketolides on resistance selection and ecologic effects during treatment for respiratory tract infections. Microb Drug Resist 2004; 10: 255-63.

35 Ackermann G, Rodloff AC. Drugs of the 21st century: telithromycin (HMR 3647) — the first ketolides. J Antimicrob Chemother 2003; 51: 497-511.

36 Zhong P, Shortridge V. The emerging new generation of antibiotics: ketolides. Curr Drug Targets Infect Disord 2001; 1: 125-31.

37 Aventis. Annual report, form 20-F, filed with the US Securities and Exchange Commission, Dec 31, 2003. Washington, DC: Aventis, 2003.

38 Clay KD, Hanson JS, Pope SD, Rissmiller RW, Purdum PP Banks PM. Brief communication: severe hepatotoxicity of telithromycin: three case reports and literature review. Ann Intern Med 2006; 144: 415-20.

39 FDA. Telithromycin (marketed as Ketek) information (revised June 29, 2006). Washington, DC: US Food and Drug Administration. http://www.fda.gov/cder/drug/infopage/ telithromycin/default.htm (accessed May 24, 2007).

40 Burger MT, Lin X, Chu DT, et al. Synthesis and antibacterial activity of novel $C_{12}$ vinyl ketolides. J Med Chem 2006; 49: 1730-43.

41 Ma Z, Clark RF, Brazzale A, et al. Novel erythromycin derivatives with aryl groups tethered to the C- 6 position are potent protein synthesis inhibitors and active against multidrug-resistant respiratory pathogens. J Med Chem 2001; 44: 4137-56.

42 Zhanel GG, Karlowsky JA, Rubinstein E, Hoban DJ. Tigecycline: a novel glycylcycline antibiotic. Expert Rev Anti Infect Ther 2006; 4: 9-25. 
43 Stein GE, Craig WA. Tigecycline: a critical analysis. Clin Infect Dis 2006; 43: 518-24.

44 Rose WE, Rybak MJ. Tigecycline: first of a new class of antimicrobial agents. Pharmacotherapy 2006; 26: 1099-110.

45 Frampton JE, Curran MP. Tigecycline. Drugs 2005; 65: 2623-35.

46 Rubinstein E, Vaughan D. Tigecycline: a novel glycylcycline. Drugs 2005; 65: 1317-36.

47 Bloomberg News. FDA approves new antibiotic from Wyeth. New York Times (New York), June 17, 2005: C4.

48 Wang L, Barrett JF. Pharmacoeconomics of treatment with the newer anti-Gram-positive agents. Expert Opin Pharmacother 2006; 7: 885-97.

49 Paterson DL. Clinical experience with recently approved antibiotics. Curr Opin Pharmacol 2006; 6: 486-90.

50 Heller MA, Eisenberg RS. Can patents deter innovation? The anticommons in biomedical research. Science 1998; 280: 698-701.

51 MSF. Call for moratorium on trade provisions that threaten access to medicines or treatment programmes. Toronto. Canada: Médecins Sans Frontières, Aug 17, 2006. http://www.msf.org/ msfinternational/invoke.cfm?objectid=1D04D94F-5056-AA77-6CC3 51A5BE86A965\&component=toolkit.article\&method=full_html (accessed June 28, 2007).

52 Aiello AE, King NB, Foxman B. Antimicrobial resistance and the ethics of drug development. Am J Public Health 2006; 96: 1910-14.

53 Outterson K. Pharmaceutical arbitrage: balancing access and innovation in international prescription drug markets. Yale J Health Policy Law Ethics 2005; 5: 193-291.

54 Towse A. A review of IP and non-IP incentives for R\&D for diseases of poverty. What type of innovation is required and how can we incentivize the private sector to deliver it? Submission to the WHO Commission on Intellectual Property Rights, Innovation and Public Health, April 28, 2005.

55 Moran M. Fast track options as a fundraising mechanism to support R\&D into neglected diseases. Pharmaceutical R\&D Policy Project. London: London School of Economics, January, 2005.

56 Moran M. A breakthrough in R\&D for neglected diseases: new ways to get the drugs we need. PLoS Med 2005; 2: 828-32.

57 Jones TM. Transferable intellectual property rights (TIPR) to incentivise R\&D for neglected diseases. WHO Commission on Intellectual Property Rights, Innovation and Public Health, Public Health e-Forum, Nov 11-Dec 22, 2004.

58 Maurer SM. The right tool(s): designing cost-effective strategies for neglected disease research. Berkeley: University of California March 29, 2005. http://gspp.berkeley.edu/iths/MAURER_ DrugRsch.pdf (accessed June 28, 2007).

59 IMS Health. Antibiotic sales data, calendar year 2005. Cambridge, UK: IMS Health, 2005.

60 Generic Pharmaceutical Association. Legislation promoted as a countermeasure against bioterrorism would counter bipartisan measures to constrain prescription costs: press release. Arlington, VA: Generic Pharmaceutical Association, Feb 8, 2005.

61 Generic Pharmaceutical Association. Brand Pharma giveaways like "wild cards" and "special" patent extensions are the wrong answer to countermeasure development: press release. Arlington, VA: Generic Pharmaceutical Association, April 29, 2005.

62 FDA. List of orphan products designated year to date 2004. Washington, DC: US Food and Drug Administration, 2004

63 Outterson K. The vanishing public domain: antibiotic resistance, pharmaceutical innovation and Intellectual Property Law. Univ Pittsbg Law Rev 2006; 67: 67-123.
64 PhRMA. Pharmaceutical industry profile 2006, table 2. http://www. phrma.org/files/Profile\%202007.pdf (accessed June 28, 2007).

65 Chaudhuri S, Goldberg PK, Jia P. Estimating the effects of global patent protection in pharmaceuticals: a case study of quinolones in India. NBER Working Paper No. 10159 (revised July, 2006). http:// papers.nber.org/papers/w10159.pdf (accessed June 28, 2007).

66 Coast J, Smith RD, Millar MR. An economic perspective on policy to reduce antimicrobial resistance. Soc Sci Med 1998; 46: 29-38.

67 Laxminarayan R. How broad should the scope of antibiotics patents be? Am J Agric Econ 2002; 84: 1287-92.

68 Kades E. Preserving a precious resource: rationalizing the use of antibiotics. Nw Univ Law Rev 2005; 99: 611-53.

69 Horowitz JB, Moehring HB. How property rights and patents affect antibiotic resistance. Health Economics 2003; 13: 575-83.

70 Pfizer Inc. Annual report, form 10-K, filed with the US Securities and Exchange Commission, Dec 31, 2005. Washington, DC: Pfizer, Inc, 2005.

71 Abrams TW. Warning letter to Pfizer. July 20, 2005. http://www.fda. gov/cder/warn/2005/Zyvox_wl.pdf (accessed June 28, 2007).

72 Harris G. Halt is urged for trials of antibiotic in children. New York Times (New York), June 8, 2006.

73 Associated Press. Enrollment of children is drug study is halted. New York Times (New York), June 9, 2006.

74 ASM Task Force on Antibiotic Resistance. Report of the American Society for Microbiology Task Force on Antibiotic Resistance. Washington, DC: American Society for Microbiology, 1994: 3-6. http://www.asm.org/ASM/files/CCPAGECONTENT/ DOCFILENAME/0000005962/antibiot\%5B1\%5D.pdf (accessed June 28, 2007)

75 Harbarth S, Masuet-Aumatell C, Schrenzel J, et al. Evaluation of rapid screening and pre-emptive contact isolation for detecting and controlling methicillin-resistant Staphylococcus aureus in critical care: an interventional cohort study. Crit Care 2006; 10: R25.

76 Zirakzadeh A, Patel R. Vancomycin-resistant enterococci: colonization, infection, detection, and treatment. Mayo Clin Proc 2006; 81: 529-36.

77 Gorbach SL. Antimicrobial use in animal feed-time to stop. N Engl J Med 2001; 345: 1202-03.

78 Mathews AW, Goldfarb Z. FDA bans use of antibiotic in poultry. Wall Street Journal (New York), July 29, 2005: B1.

79 Council Regulation (EC) No 2821/98 of December 17, 1998. Brussels: European Union.

80 Laxminarayan R, Over M, Smith DL. Will a global subsidy of new antimalarials delay the emergence of resistance and save lives? Health Aff 2006; 25: 325-36.

81 Laufer K, Thesing PC, Eddington ND, et al. Return of chloroquine antimalarial efficacy in Malawi. N Engl J Med 2006; 355: 1959-66.

82 Love J, Hubbard T. The big idea: prizes to stimulate R\&D for new medicines. KEI Research Paper 2007: 1 (revised March 26, 2007). http://www.keionline.org/misc-docs/bigidea-prizes.pdf (accessed June 28, 2007)

83 Stiglitz JE. Scrooge and intellectual property rights: a medical prize fund could improve the financing of drug innovations. BMJ 2006; 333: $1279-80$.

84 Outterson K. Patent buy-outs for global disease innovations for lowand middle-income countries. Am J Law Med 2006; 32: 159-73.

85 Projan SJ. Why is big pharma getting out of antibacterial drug discovery? Curr Opin Microbiol 2003; 6: 1-4. 